\title{
Left ventricular assist device as destination therapy in cardiac end-stage dystrophinopathies: Midterm results
}

\author{
Gianluigi Perri, MD, PhD, ${ }^{\text {a,b,c }}$ Sergio Filippelli, MD, $\mathrm{PhD},{ }^{\mathrm{a}}$ Rachele Adorisio, $\mathrm{MD},{ }^{\mathrm{a}}$ \\ Roberta Iacobelli, MD, PhD, ${ }^{\mathrm{a}}$ Francesca Iodice, $\mathrm{MD}, \mathrm{PhD},{ }^{\mathrm{a}}$ Giuseppina Testa, MD, \\ Maria Giovanna Paglietti, MD, ${ }^{b}$ Domenico D'Amario, MD, PhD, ${ }^{\mathrm{c}}$ Massimo Massetti, $\mathrm{MD},{ }^{\mathrm{c}}$ and \\ Antonio Amodeo, $\mathrm{MD}^{\mathrm{a}}$
}

\section{ABSTRACT}

Objective: We report our experience with the use of a left ventricular assist device (LVAD) as destination therapy (DT) for the management of patients with cardiac end-stage dystrophinopathies.

Methods: From February 2011 to February 2016, 7 patients with dystrophinopathies and dilated cardiomyopathy (DCM) were treated with LVADs at our institution. Median age at surgery was 16.5 years (range, 14.2-23.4 years). All patients were preoperatively evaluated by a multidisciplinary team approach.

Results: All patients survived to hospital discharge. The early postoperative course was characterized by abdominal bleeding (1 patient) and retropharyngeal bleeding (1 patient). Because of abdominal or retropharyngeal bleeding, both required postoperative heparin infusion discontinuation for 35 and 33 days, respectively. Among the late complications, 1 child developed osteolysis and infection at the pedestal site of the device, which required surgical displacement; 1 patient required gastrostomy as a result of poor feeding, and another had a cerebral stroke, which was treated with percutaneous thrombus aspiration. The other 2 patients did not show early or late complications. At a median follow-up time of 21.7 months (range, 3-45 months) there have been 3 deaths: 1 patient died of a lung infection after 45 months, 1 died of tracheal bleeding after 29 months, and 1 died of cerebral hemorrhage after 14 months.

Conclusions: Our experience indicates that the use of an LVAD as DT in patients with dystrophinopathies with end-stage DCM is feasible, suggesting that it may be suitable as a palliative therapy for the treatment of these patients with no other therapeutic options. (J Thorac Cardiovasc Surg 2017;153:669-74)

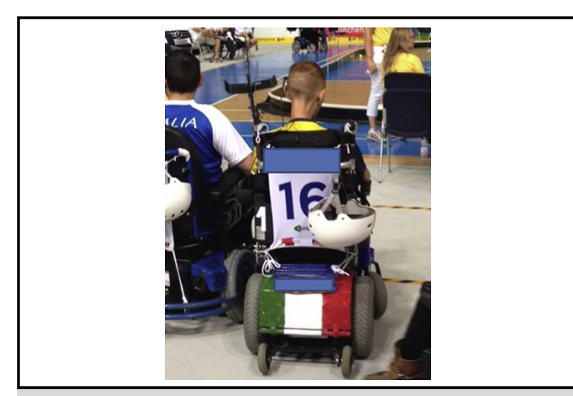

Patients with LVAD-DMD participate in the hockey wheelchair world championship.

\section{Central Message}

Our experience showed the possibility of using a left ventricular assist device as destination therapy in patients with dystrophinopathies with end-stage dilated cardiomyopathy.

\section{Perspective}

End-stage cardiomyopathy is the main cause of mortality in patients with dystrophinopathies. These patients present a difficult challenge because every single step is characterized by a fine balance between risks and benefits. Our results suggest that the use of VAD may be considered a palliative therapy ensuring an adequate time-limited quality of life in children with no other therapeutic options.

See Editorial Commentary page 675

See Editorial page 667.

\footnotetext{
From the ${ }^{\mathrm{a} D e p a r t m e n t ~ o f ~ P e d i a t r i c ~ C a r d i o l o g y ~ a n d ~ C a r d i a c ~ S u r g e r y, ~ a n d ~}{ }^{\mathrm{b}}$ Pneumology Unit - University Hospital Pediatric Department, Bambino Gesù Children Hospital, IRCCS; and ${ }^{\mathrm{c} C a r d i o v a s c u l a r}$ Science, Cardio-Thoracic Surgery Unit, Catholic University, A. Gemelli Hospital, Rome, Italy.

Read at the 96th Annual Meeting of The American Association for Thoracic Surgery, Baltimore, Maryland, May 14-18, 2016.

Received for publication May 29, 2016; revisions received July 16, 2016; accepted for publication Aug 8, 2016; available ahead of print Sept 29, 2016.

Address for reprints: Gianluigi Perri, MD, PhD, Department of Pediatric Cardiology and Cardiac Surgery Bambino Gesù Children's Hospital IRCCS Piazza S. Onofrio, 4 - 00165 Roma, Italy (E-mail: dr.gianluigiperri@gmail.com).

$0022-5223 / \$ 36.00$

Copyright $\odot 2016$ by The American Association for Thoracic Surgery

http://dx.doi.org/10.1016/j.jtcvs.2016.08.016
}

The dystrophinopathies include a spectrum of muscular dystrophy phenotypes with variable involvement of skeletal and cardiac muscle. ${ }^{1}$ Duchenne muscular dystrophy (DMD) is an X-linked muscular disease responsible for over $80 \%$

Scanning this QR code will take you to the article title page.

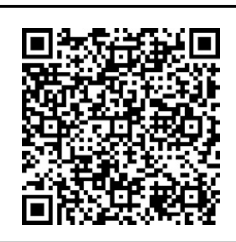




$$
\begin{aligned}
& \text { Abbreviations and Acronyms } \\
& \text { CPB = cardiopulmonary bypass } \\
& \text { DCM }=\text { dilated cardiomyopathy } \\
& \text { DT }=\text { destination therapy } \\
& \text { DMD }=\text { Duchenne muscular dystrophy } \\
& \text { HF }=\text { heart failure } \\
& \text { HTx }=\text { heart transplantation } \\
& \text { LV }=\text { left ventricle } \\
& \text { LVAD } \\
& \text { NIV } \text { left ventricular assist device } \\
& \text { RV }=\text { right ventricle } \\
& \text { VAD }=\text { ventricular assist device }
\end{aligned}
$$

of all muscular dystrophies caused by the absence of dystrophin, a protein that links the cytoskeleton to the extracellular matrix. ${ }^{2}$ Respiratory failure as a result of respiratory muscle weakness and chest deformity (kyphoscoliosis), along with respiratory infections, has been considered the most common cause of death. ${ }^{3}$ Nowadays, with the improvement in ventilatory support, particularly with the use of noninvasive nocturnal ventilation (NIV), the natural history of this disease has changed and cardiac complications such as dilated cardiomyopathy (DCM) have become the main cause of mortality $(>40 \%) .{ }^{4} \mathrm{DCM}$ in DMD is characterized by a progressive development of fibrosis that extends from the epicardium to the endocardium, starting from the inferior posterior wall down toward the apex and around the heart, ${ }^{5-7}$ which allows progressive impairment of the left ventricular ejection fraction until the occurrence of clinical heart failure (HF). There is a higher mortality for DMD cardiomyopathy compared with other DCMs. ${ }^{8}$ Several studies have demonstrated that the incidence of DCM in patients with dystrophinopathies increases progressively with age: $25 \%$ of patients have cardiomyopathy by the age of 6 years, $9 \%$ are affected between 6 and 10 years, and by adulthood ( $>20$ years old) all patients have signs of cardiac impairment. ${ }^{9-11}$ Although heart transplantation (HTx) remains the surgical procedure of choice for children with severe advanced $\mathrm{HF}^{12,13}$ dystrophinopathies have generally been considered a contraindication for HTx because of the possibility of respiratory failure and progressive skeletal myopathy leading to limited functional capacity. ${ }^{14,15}$ An alternative treatment for endstage HF in dystrophinopathies is the use of left ventricular assist devices (LVAD) as destination therapy (DT). We have used the Jarvik 2000 LVAD (Jarvik Heart, Inc, New York); this is a thumb-sized axial flow impeller pump, weighing $90 \mathrm{~g}$, and with a wide displacement volume of $25 \mathrm{~cm} .{ }^{16}$ The impeller spins within an electromagnetic field of between 8000 and 120,000 rpm, delivering a systemic blood flow of 3-8 L/min depending on the systemic vascular resistance, and with a power consumption of less than $12 \mathrm{~W} .{ }^{17}$ Recently, our group reported the first case of LVAD as DT in a patient with DMD. ${ }^{18}$ In the present study, we report our midterm results with the use of LVAD as DT for the management of end-stage HF in patients with dystrophinopathies.

\section{METHODS}

We retrospectively reviewed medical and surgical records, discharge summaries, and clinical follow-up data of all consecutive patients with dystrophinopathies and DCM treated with LVAD at Bambino Gesù Children Hospital in Rome from February 2011 to February 2016. Approval from the Institutional Scientific Board of the Bambino Gesù Children's Hospital was obtained. We collected data on sex, age, and weight at surgery, type of dystrophinopathy, type of surgical approach, intra- and post-operative management, hospital stay, and postoperative complications. All patients were followed by our Out-Patients Heart Failure Service and were admitted to our institution for acute HF. Three patients required noninvasive positive pressure ventilation (NIV) before hospital admission for respiratory impairment. Preoperatively, all were evaluated by a multidisciplinary approach including anesthesiology, cardiology, cardiothoracic surgery, neurology, pulmonology, hematology, ear nose and throat specialists, orthopedic surgery, infectious diseases specialists, psychology, and physiotherapy. Our criteria for choosing patients for LVAD implant are dependence on intravenous inotropic support and a cardiac index $<1.5$. Otherwise, absolute contraindications are, in addition to those normally used for LVAD surgery, 24 hours of NIV, tracheostomy, and noncompliance of family. All patients were wheelchair dependent, except for 1 who was able to ambulate for a short time without any support. Follow-up was complete in all patients $(100 \%)$. After LVAD implantation, our followup program provides a cardiologic evaluation once a month, and nutritional and respiratory assessment is performed every 6 months. Median preoperative albumin was $4.3 \mathrm{~g} / \mathrm{dL}$ (range, $4-4.6 \mathrm{~g} / \mathrm{dL}$ ) and median postoperative albumin was $3.9 \mathrm{~g} / \mathrm{dL}$ (range, $3.5-4.5 \mathrm{~g} / \mathrm{dL}$ ). The median preoperative total protein value was $7.2 \mathrm{~g} / \mathrm{dL}$ (range, 7-7.4 g/dL), while the median postoperative value was $7.4 \mathrm{~g} / \mathrm{dL}$ (range, 6.4-7.9 g/dL). The primary outcomes of our analysis were early and late death defined as any condition related to LVAD implantation that caused death within or after 30 days from surgery, respectively.

\section{Preoperative Assessment}

In the preoperative assessment for LVAD surgery, particular care was taken to evaluate right ventricle (RV) function because, as reported elsewhere, ${ }^{19,20} \mathrm{RV}$ failure is one of the most important complications of postoperative LVAD implantation. Before surgery in our center, all patients underwent echocardiography, magnetic resonance imaging, right and left catheterization, pulmonary function testing, and full laboratory work-up. A computed tomography scan of the head is routinely performed to assess the area of the skull where the pedestal will be implanted (bone thickness should be at least $4 \mathrm{~mm}$ ). A multidisciplinary approach taking into account all comorbidities is mandatory to select candidates for LVAD. The central goal of patient-centric care requires that the patient and the family are sufficiently educated about the alternatives available so that their expectations can be met as fully as possible.

\section{Surgical Technique}

The first step is the implantation of the titanium pedestal into the skull behind the mastoid access. ${ }^{21}$ A periosteal flap is generally carried out in a relatively flat area of the skull where the position of the titanium base has been previously marked. ${ }^{22}$ The entry site for the pedestal is covered with an autologous pericardial patch with a central hole to allow the exit of the 
TABLE 1. Postoperative course and final outcome of our patients

\begin{tabular}{|c|c|c|c|c|c|c|c|c|c|c|}
\hline Patient & $\begin{array}{l}\text { Primary } \\
\text { diagnosis }\end{array}$ & $\begin{array}{c}\text { Age at } \\
\text { surgery } \\
(y)\end{array}$ & $\begin{array}{c}\text { Weight at } \\
\text { surgery } \\
(\mathrm{kg})\end{array}$ & $\begin{array}{l}\text { Type of } \\
\text { surgery }\end{array}$ & $\begin{array}{c}\text { Early } \\
\text { complications }\end{array}$ & $\begin{array}{c}\text { In-hospital } \\
\text { death }\end{array}$ & $\begin{array}{c}\text { Late } \\
\text { complications }\end{array}$ & Outcome & $\begin{array}{c}\text { Cause of } \\
\text { death }\end{array}$ & $\begin{array}{c}\text { Length of } \\
\text { follow-up (d) }\end{array}$ \\
\hline 1 & DMD & 17.4 & 50 & $\begin{array}{l}\text { On-pump } \\
\text { LVAD }\end{array}$ & None & No & Gastrostomy & Death & $\begin{array}{l}\text { Cerebral } \\
\text { hemorrhage }\end{array}$ & 456 \\
\hline 2 & DMD & 15.6 & 36 & $\begin{array}{l}\text { On-pump } \\
\text { LVAD }\end{array}$ & $\begin{array}{l}\text { Retropharyngeal } \\
\text { bleeding and } \\
\text { cholecystectomy }\end{array}$ & No & None & Alive & & 1243 \\
\hline 3 & DMD & 14.2 & 34 & $\begin{array}{l}\text { On-pump } \\
\text { LVAD }\end{array}$ & $\begin{array}{l}\text { Abdominal bleeding } \\
\text { and splenectomy }\end{array}$ & No & None & Death & $\begin{array}{c}\text { Severe ORL } \\
\text { bleeding }\end{array}$ & 859 \\
\hline 4 & DMD & 15.6 & 43 & $\begin{array}{l}\text { On-pump } \\
\text { LVAD }\end{array}$ & None & No & $\begin{array}{l}\text { Osteolysis and } \\
\text { infection at } \\
\text { the pedestal } \\
\text { site }\end{array}$ & Death & Lung infection & 1344 \\
\hline 5 & DMD & 23.4 & 45 & $\begin{array}{l}\text { Off-pump } \\
\text { LVAD }\end{array}$ & None & No & None & Alive & & 229 \\
\hline 6 & $\begin{array}{l}\beta 2 \text { sarcoglycan } \\
\text { deficit }\end{array}$ & 17.4 & 70 & $\begin{array}{l}\text { On-pump } \\
\text { LVAD }\end{array}$ & None & No & $\begin{array}{r}\text { Cerebral } \\
\text { stroke }\end{array}$ & Alive & & 437 \\
\hline 7 & DMD & 15.3 & 52 & $\begin{array}{l}\text { On-pump } \\
\text { LVAD }\end{array}$ & None & No & None & Alive & & 66 \\
\hline
\end{tabular}

$D M D$, Duchenne muscular dystrophy; $L V A D$, left ventricular assist device; $O R L$, otorhinolaryngology.

connection tube, and the power cable is tunneled from the mastoid to the mediastinum below the medial part of the sternocleidomastoideus muscle and the anonymous venous trunk. After pedestal implantation, the second step is the insertion of the device. LVAD surgery was performed in all patients through standard median sternotomy on mildly hypothermic cardiopulmonary bypass (CPB). The choice of the LV apex site implantation is made under transesophageal echocardiographic guidance. A special coring knife is inserted through a cruciate incision and, after removal of the myocardial core, the Jarvik 2000 pump is inserted within the LV apex. Subsequently, the outflow graft is routed around the heart over the superior vena cava in the lateral side of the ascending aorta. The outflow graft is covered at the level of the inferior vena cava angle with a Gore-Tex graft (W.L. Gore and Associates, Inc, Flagstaff, Ariz) to avoid compression from the heart. The ascending aorta is partially occluded with a size clamp, and end-to-side anastomosis is performed with a continuous 4-0 Prolene (Ethicon, Inc, Nordersted, Germany) suture. In 1 patient, we used a minimally invasive approach without CPB. A left anterior minithoracotomy on the sixth intercostal space was performed for the intraventricular implantation of the Jarvik 2000, and a subcomplete median sternotomy from the second to the fourth intercostal space (preserving the xiphoid appendage together with the insertion of the rectus abdominis muscles) was carried out for the outflow graft anastomosis to the aorta.

\section{RESULTS}

Seven patients with dystrophinopathies and DCM underwent LVAD as DT at our institution during the study period (Table 1). Based on the primary diagnosis, 6 patients had DMD, and 1 had a $\beta 2$ sarcoglycan deficit. Median age and weight at surgery were 16.5 years (range, 14.2-23.4 years) and $44 \mathrm{~kg}$ (range, $34-70 \mathrm{~kg}$ ), respectively. Six patients received LVAD after long-term medical intravenous inotropic support, and 1 underwent implantation after 12 days of veno-arterial extracorporeal membrane oxygenation. All patients, preoperatively and after extubation, underwent NIV, cough machine cycles, and a preconditioning cycle with levosimendan 72 hours before Jarvik implantation. Median hospital stay was 77 days (range, 35-180 days). One patient with severe scoliosis experienced, in the early postoperative course, a spleen lesion during the insertion of a chest drain. This led to abdominal bleeding, which required splenectomy and several abdominal surgical revisions. Because of abdominal bleeding, anticoagulation therapy was suspended for 32 days without any pump complications. In another child, on the 13th postoperative day, as a consequence of nasogastric tube placement, severe retropharyngeal bleeding and tongue edema occurred, which required new intubation. A few days later, the presence of a bilateral pleural effusion required the placement of a chest drain, which was complicated by thorax bleeding and a surgical revision was performed. Discontinuation of heparin infusion for 35 days was necessary because of the retropharyngeal bleeding with several otolaryngologic surgical revisions. The same patient developed postoperative gallstones, which were treated by cholecystectomy. Another patient required gastrostomy 10 months after VAD insertion due to poor feeding. After 1 year, the first patient with DMD developed osteolysis and infection at the pedestal site of the device (caused by inappropriate head position during sleep), which required surgical displacement of the pedestal and antibiotic therapy for 6 months (Figure 1). Moreover, after 1 year, the patient with the $\beta 2$ sarcoglycan deficit had a cerebral stroke, which was treated within 3 hours at the Stroke Unit, with percutaneous thrombus aspiration at the cerebral media artery without any neurologic sequelae. The other 2 patients did not show any early or late complications. All patients survived to hospital discharge; however, there were 3 late 


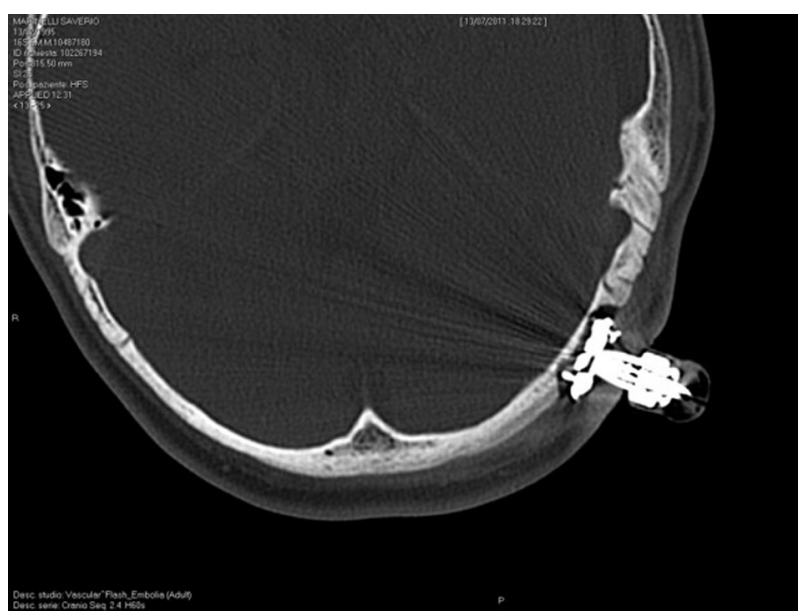

FIGURE 1. Computed tomography scan showing osteolysis and infection of the pedestal.

deaths at a median follow-up time of 22 months (range, 3-45 months): 1 patient died of sepsis due to Staphylococcus aureus lung infection after 45 months; another patient, with a tracheostomy, died in a peripheral hospital of tracheal bleeding due to an inappropriate otorhinolaryngology maneuver after 29 months; and the other died of cerebral hemorrhage after 15 months of LVAD implantation.

\section{DISCUSSION}

End-stage cardiomyopathy is one of the complications of dystrophinopathies, leading to progressive left ventricular dysfunction and advanced HF. Until the last decade, respiratory failure that occurred earlier than cardiac failure was the main cause of death. Respiratory care has greatly improved, and DCM is the main cause of morbidity and mortality in patients with DMD up to the third or fourth decade of life. ${ }^{8}$ This subgroup of patients currently represents a newly emerging therapeutic challenge. ${ }^{18}$ In 2010 , The DMD Care Considerations Working Group expanded the existing traditional therapies with novel HF therapies such as mechanical circulatory support and implantable cardioverter-defibrillators for the management of DMD cardiomyopathy. Although the best approach remains unclear, it does seem clear that treatment should be more aggressive. ${ }^{23}$ Until now, no definitive therapy has been found to reverse or cure the cardiac and skeletal alterations present in these patients. Although some authors ${ }^{15}$ have shown that the long-term clinical outcomes of HTx in selected patients with dystrophinopathies are similar to a matched cohort of patients who undergo transplantation for idiopathic DCM, there is a reluctance to offer cardiac transplantation to these patients with a limited life expectancy in an era of donor shortage. Therefore, the alternative therapeutic option is the use of LVAD. Ryan and colleagues $^{24}$ reported their experience with the HeartMate II device in 2 patients with DMD with end-stage DCM. In our group of children, we prefer to use the Jarvik 2000 VAD. The main advantage of this device in DMD wheelchair-dependent patients is related to the positioning of the power cable in the retroauricular site, with a consequently lower risk of infection compared with an abdominal cable. Accurate and appropriate selection of patients DMD suitable for VAD surgery is necessary because this group of patients represents a difficult challenge, where every single step is characterized by a fine balance between the risks and benefits, and different variables play an important role. As previously reported by our group, ${ }^{25}$ absolute exclusion criteria are active sepsis, evidence of intrinsic hepatic or renal disease, documented heparin-induced thrombocytopenia, idiopathic purpura, documented coagulopathy, noncompliance of the family, severe respiratory insufficiency ( 24 hours NIV or tracheostomy), and severe RV dysfunction.

This class of patients requires a series of clinical and surgical precautions and maneuvers that are possible only in centers with a high level of experience of patients with DMD, especially in the postoperative phase. Indeed, according to our experience, the presence of comorbidities such as severe kyphoscoliosis and respiratory muscle weakness, which are common in the patient with advanced DMD, may increase intraoperative risks and postoperative complications. With regard to the surgical technique, we preferred to avoid the left thoracotomy approach, commonly used in adult patients during VAD implantation, because of the respiratory insufficiency of our patients. Moreover, all surgical implantations were performed using CPB except in 1 patient where we performed a minimally invasive off-pump VAD implantation through a left anterior minithoracotomy. This approach allowed us to further reduce postoperative respiratory impairment related to $\mathrm{CPB}$ and to a complete sternotomy by preserving the respiratory muscle insertion on the xiphoid process. Similarly, we strongly suggest the use of postoperative NIV because it allows the reduction of postoperative respiratory insufficiency caused by the presence of scoliosis and muscle weakness, through reduction of the work involved in breathing, improvement of alveolar recruitment with better gas exchange, reduction of LV afterload with increasing $\mathrm{CO}$, and by improving hemodynamics. ${ }^{25}$ Our experience shows that postoperative care can be extremely challenging and is often burdened by unexpected complications. Severe kyphoscoliosis, resulting in chest deformity and an abnormally elevated diaphragm, needs particular care in routine maneuvers such as chest drain placement because of the potential risk of abdominal organ damage, as happened in our patient. Furthermore, each postoperative cardiac, and especially extracardiac, complication must be managed only in a specialized center because the morbidity and mortality related to inadequate therapeutic maneuvers may be high. Indeed, 1 of our patients died in a peripheral 
hospital because they underwent bronchoscopic examination with an endoscope that caused severe and intractable retropharyngeal bleeding. Postoperative anticoagulation management may be challenging in patients with DMD. ${ }^{26}$ We have developed a standard protocol including attention to intra- and postoperative blood loss, and use of tranexamic acid and prothrombin complexes. ${ }^{25}$ However, in the case of postoperative bleeding we have been forced to suspend anticoagulation therapy for 32 or 35 days without VAD function complications. In conclusion, the prolonged life expectancy of patients with DMD up to the third or fourth decade of life incurs the problem of DCM being the main cause of death. Preoperative patient selection and an accurate surgical strategy with multidisciplinary postoperative management are mandatory to ensure good early and midterm results in patients who have DMD with VAD. We show the possibility of using VAD as DT in patients with dystrophinopathies with end-stage DCM to ensure an acceptable quality of life.

According to the basic philosophy of palliative care, which is to achieve the best quality of life for patients even when their illness cannot be cured, ${ }^{27}$ our results suggest that the use of VAD as DT may be a palliative, time-limited therapy for the treatment of patients with no other therapeutic options.

\section{Webcast}

You can watch a Webcast of this AATS meeting presentation by going to: http://webcast.aats.org/2016/Video/ Wednesday/05-18-16_Ballroom_III_0730_Perri-800.mp4.

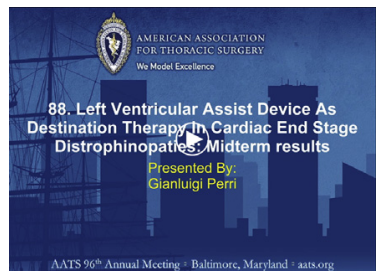

\section{Conflict of Interest Statement}

Authors have nothing to disclose with regard to commercial support.

\section{References}

1. Brandsema JF, Darras BT. Dystrophinopathies. Semin Neurol. 2015;35:369-84.

2. Lapidos KA, Kakkar R, McNally EM. The dystrophin glycoprotein complex: signaling strength and integrity for the sarcolemma. Circ Res. 2004;94:1023-31.

3. Manzur AY, Kinali M, Muntoni F. Update on the management of Duchenne muscular dystrophy. Arch Dis Child. 2008;93:986-90.

4. Fayssoil A, Nardi O, Orlikowski D, Annane D. Cardiomyopathy in Duchenne muscular dystrophy: pathogenesis and therapeutics. Heart Fail Rev. 2010;15:103-7.

5. Frankel KA, Rosser RJ. The pathology of the heart in progressive muscular dystrophy: epimyocardial fibrosis. Hum Pathol. 1976;7:375-86.

6. Moriuchi T, Kagawa N, Mukoyama M, Hizawa K. Autopsy analyses of the muscular dystrophies. Tokushima J Exp Med. 1993;40:83-93.
7. James TN. Observations on the cardiovascular involvement, including the cardiac conduction system, in progressive muscular dystrophy. Am Heart J 1962;63:48-56.

8. McNally EM, Kaltman JR, Benson DW, Canter CE, Cripe LH, Duan D, et al; Working Group of the National Heart, Lung, and Blood Institute; Parent Project Muscular Dystrophy. Contemporary cardiac issues in Duchenne muscular dystrophy. Working Group of the National Heart, Lung, and Blood Institute in collaboration with Parent Project Muscular Dystrophy. Circulation. 2015;131:1590-8.

9. Hor KN, Wansapura J, Markham LW, Mazur W, Cripe LH, Fleck R, et al. Circumferential strain analysis identifies strata of cardiomyopathy in Duchenne muscular dystrophy: a cardiac magnetic resonance tagging study. J Am Coll Cardiol. 2009;53:1204-10.

10. Eagle M, Baudouin SV, Chandler C, Giddings DR, Bullock R, Bushby K. Survival in Duchenne muscular dystrophy: improvements in life expectancy since 1967 and the impact of home nocturnal ventilation. Neuromuscul Disord. 2002;12:926-9.

11. Connuck DM, Sleeper LA, Colan SD, Cox GF, Towbin JA, Lowe AM, et al Pediatric Cardiomyopathy Registry Study Group. Characteristics and outcomes of cardiomyopathy in children with Duchenne or Becker muscular dystrophy: a comparative study from the Pediatric Cardiomyopathy Registry. Am Heart J. 2008;155:998-1005.

12. Hunt SA, Abraham WT, Chin MH, Feldman AM, Francis GS, Ganiats TG, et al ACC/AHA 2005 guideline update for the diagnosis and management of chronic heart failure in the adult: a report of the American College of Cardiology/American Heart Association Task Force on Practice Guidelines (Writing Committee to Update the 2001 Guidelines for the Evaluation and Management of Heart Failure). Circulation. 2005;112:e154-235.

13. Jessup M, Costanzo MR. The cardiorenal syndrome: do we need a change of strategy or a change of tactics? J Am Coll Cardiol. 2009;53:597-9.

14. Chun JL, O'Brien R, Berry SE. Cardiac dysfunction and pathology in the dystrophin and utrophin-deficient mouse during development of dilated cardiomyopathy. Neuromuscul Disord. 2012;22:368-79.

15. Wu RS, Gupta S, Brown RN, Yancy CW, Wald JW, Kaiser P, et al. Clinical outcomes after cardiac transplantation in muscular dystrophy patients. J Heart Lung Transplant. 2010;29:432-8.

16. Westaby S, Banning AP, Jarvik R, Frazier OH, Pigott DW, Jin XY, et al. First permanent implant of the Jarvik 2000 Heart. Lancet. 2000;356:900-3.

17. Westaby S, Katsumata T, Houel R, Evans R, Pigott D, Frazier OH, et al. The Jarvik 2000 Heart: potential for bridge to myocyte recovery. Circulation. 1998; 98:1568-74.

18. Amodeo A, Adorisio R. Left ventricular assist device in Duchenne cardiomyopathy: can we change the natural history of cardiac disease? Int J Car diol. 2012;161:e43.

19. Palmer B, Lampert B, Mathier MA. Management of right ventricular failure in pulmonary hypertension (and after LVAD implantation). Curr Treat Options Cardiovasc Med. 2013; 15:533-43.

20. Meineri M, Van Rensburg AE, Vegas A. Right ventricular failure after LVAD implantation: prevention and treatment. Best Pract Res Clin Anaesthesiol. 2012;26:217-29.

21. Parkin JL. Percutaneous pedestal in cochlear implantation. Ann Otol Rhinol Laryngol. 1990;99:796-800.

22. Westaby S, Frazier OH, Pigott DW, Saito S, Jarvik RK. Implant technique for the Jarvik 2000 Heart. Ann Thorac Surg. 2002;73:1337-40.

23. Bushby K, Finkel R, Birnkrant DJ, Case LE, Clemens PR, Cripe L, et al. DMD Care Considerations Working Group. Diagnosis and management of Duchenne muscular dystrophy, part 2: implementation of multidisciplinary care. Lancet Neurol. 2010;9:177-89.

24. Ryan TD, Jefferies JL, Sawnani H, Wong BL, Gardner A, Del Corral M, et al Implantation of the HeartMate II and HeartWare left ventricular assist devices in patients with duchenne muscular dystrophy: lessons learned from the first applications. ASAIO J. 2014;60:246-8.

25. Iodice F, Testa G, Averardi M, Brancaccio G, Amodeo A, Cogo P. Implantation of a left ventricular assist device as a destination therapy in Duchenne muscular dystrophy patients with end stage cardiac failure: management and lessons learned. Neuromuscul Disord. 2015;25:19-23.

26. Forst J, Forst R, Leithe H, Maurin N. Platelet function deficiency in Duchenne muscular dystrophy. Neuromuscul Disord. 1998;8:46-9.

27. Rousseau P. Ethical and legal issues in palliative care. Prim Care. 2001;28:391-400.

Key Words: Duchenne muscolar dystrophy, left ventricular assist device 


\section{Discussion}

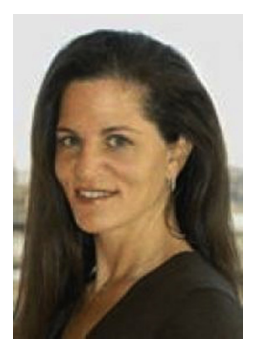

Dr K. Guleserian (Dallas, Tex). Thanks, Dr Chen, Dr Del Nido. I don't have any disclosures.

Dr Perri and colleagues, congratulations on an excellent presentation and the accompanying manuscript.

Your team has certainly taken on a very challenging group of patients. Duchenne muscular dystrophy and the other dystrophinopathies are characterized by progressive skeletal muscle weakness, inevitable loss of ambulation, and death secondary to cardiac or respiratory failure. As described, end-stage dilated cardiomyopathy is a frequent finding in these patients who are not typically considered for transplantation since survival beyond the third and fourth decades is really rare.

Your series of 7 patients includes 6 with Duchenne muscular dystrophy, the largest reported series in the world right now adding to the 4 cases in the United States first performed in Cincinnati and also by our group at UT Southwestern. That was in 2012 and 2013. Two of those patients are still alive at 2.5 years out.

Your results are commendable with no early mortality. And although the late mortality, 3 of the 7 , was just over $40 \%$, one could argue that without any intervention it would be $100 \%$.

I have 2 questions, and then I have 1 final comment after that.

So the first question: Cardiac manifestations are often masked by inactivity and respiratory muscle compromise, so how do you decide on the most optimal timing for LVAD implantation in these patients?

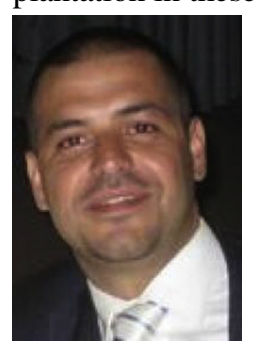

Dr Perri (Rome, Italy). Thank you for the question.

So the indication and particularly the timing when choosing the patient for VAD is difficult because the cardiac evolution of this subgroup of patients is different compared with other patients with heart failure.

Indeed, in our outpatient clinic, we have followed several patients with severe left ventricular dysfunction and $10 \%$ ejection fraction, but they are wheelchair dependent and they are in a stable hemodynamic condition and can remain in this condition for a long time.

So, actually, we choose patients for VAD if they are hospitalized and need intravenous or mechanical support.

Dr Guleserian. Thank you.

My second question, you mentioned in the manuscript that 1 of the 7 cases was performed via a left anterior minithoracotomy without the use of cardiopulmonary bypass to help reduce the risks of postoperative respiratory complications. And so given that experience, is that now your preferred approach for future patients?

Dr Perri. Yes. We performed this approach in the last patient. We believe that this approach with the left minithoracotomy allowed us to place the device without cardiopulmonary bypass and allowed early extubation of the patient.

Dr Guleserian. Great. And then just 1 final comment. Alfredo Ferrari, who was nicknamed Alfredino or Dino, was born in January 1932 in Modena, Italy. He was the son of Enzo Ferrari and the heir to the Ferrari empire. Interestingly, Dino had Duchenne muscular dystrophy. But importantly he designed the $1.5 \mathrm{~L}$ DOHC, or dual overhead camshaft, V6 engine for Formula Two racing in 1955, but sadly died 6 months later at the age of 24 years from end-stage dilated cardiomyopathy. And that was around the time that the 750 Monza, which was the predecessor to the Ferrari 250 Testa Rossa, was unveiled and before his namesake automobiles, the Fiat Dino and Dino, were able to be produced. So just a little bit of Italian history to go along with your presentation.

Dr Perri. Thank you.

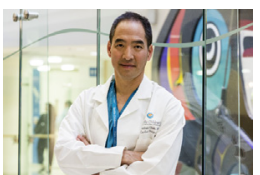

Dr Jonathan M. Chen (Seattle, Wash). I was wondering, it seemed like the few complications you had were all related to bleeding. Do you feel as though the Duchenne patients are somehow more prone to that or was that just incidental?

Dr Perri. Thank you for the question. Yes, we are extremely meticulous about intraoperative bleeding and despite some reports mentioning an alteration in hemostasis in Duchenne, we don't have data to support this. We know that the bleeding may be a postoperative complication in these patients, and we use tranexamic acid to improve intraoperative hemostasis.

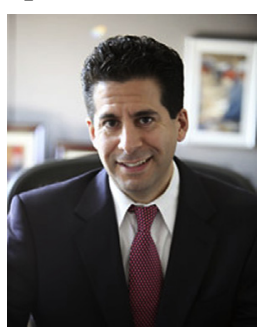

Dr D. Morales (Cincinnati, Ohio). Have you supported someone who had no use of their lower and upper extremities?

Dr Perri. No.

Dr Morales. No. So what do you feel is your cutoff in terms of their ventilator support (ie, sip vent) or extremity function?

Dr Perri. For their respiratory care?

Dr Morales. Yes.

Dr Perri. Regarding use of extremities, we don't believe that is a contraindication to VAD. We don't use sip vent, but we consider tracheostomy and 24-hour NIV a contraindication to LVAD insertion. We use early postoperative NIV and a cough machine cycle. And if no postoperative bleeding, we try to wean the patient as soon as possible from mechanical ventilation with the aim of extubating the patient within 12 hours.

NIV and the cough machine cycle, as reported in our paper, helped to improve alveolar recruitment, improve gas exchange, and reduce the work of breathing. 